\title{
ARM
}

CLIMATE RESEARCH FACILITY

\section{X-Band Scanning ARM Precipitation Radar (X-SAPR) HANDBOOK}

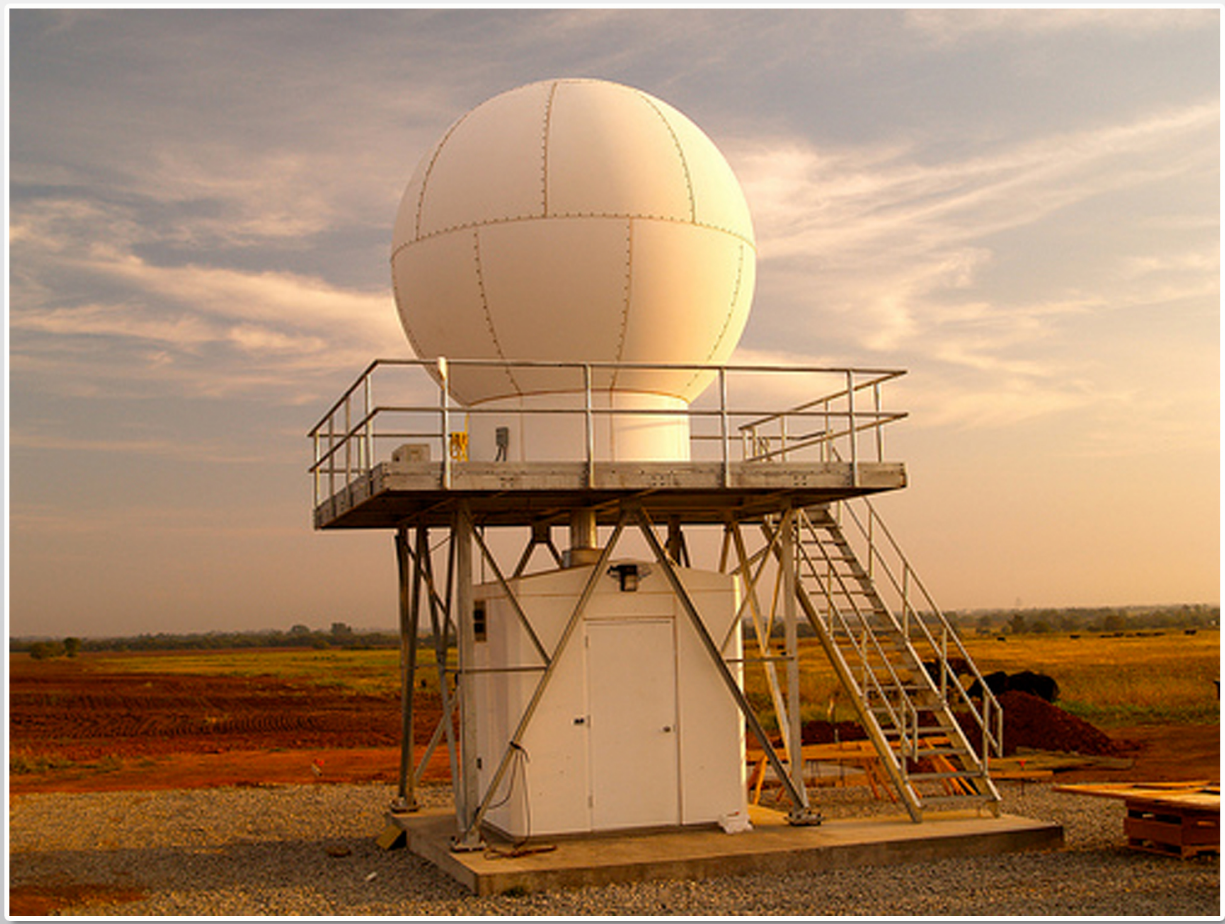

October 2012 


\section{DISCLAIMER}

This report was prepared as an account of work sponsored by the U.S. Government. Neither the United States nor any agency thereof, nor any of their employees, makes any warranty, express or implied, or assumes any legal liability or responsibility for the accuracy, completeness, or usefulness of any information, apparatus, product, or process disclosed, or represents that its use would not infringe privately owned rights. Reference herein to any specific commercial product, process, or service by trade name, trademark, manufacturer, or otherwise, does not necessarily constitute or imply its endorsement, recommendation, or favoring by the U.S. Government or any agency thereof. The views and opinions of authors expressed herein do not necessarily state or reflect those of the U.S. Government or any agency thereof. 


\section{X-band Scanning ARM Precipitation Radar (X-SAPR)}

K Widener

N Bharadwaj

October 2012

Work supported by the U.S. Department of Energy, Office of Science, Office of Biological and Environmental Research 


\section{Acronyms and Abbreviations}

\begin{tabular}{|c|c|}
\hline$\phi_{\mathrm{DP}}$ & differential phase \\
\hline$\phi_{\mathrm{HH}}$ & horizontal signal \\
\hline$\phi_{\mathrm{VV}}$ & vertical signal \\
\hline$\rho_{\mathrm{HV}}$ & dual-polarization correlation magnitude \\
\hline $3 \mathrm{D}$ & three-dimensional \\
\hline ARM & Atmospheric Radiation Measurement (Climate Research Facility) \\
\hline $\mathrm{BIT}$ & built-in-test (messages) \\
\hline CCDB & Common Calibration Database \\
\hline $\mathrm{dB}$ & decibel \\
\hline $\mathrm{dBi}$ & antenna gain referenced to isotropic radiator \\
\hline $\mathrm{dBm}$ & decibel referenced to $1 \mathrm{~mW}$ \\
\hline $\mathrm{dBZ}$ & reflectivity \\
\hline $\mathrm{GHz}$ & gigahertz $\left(10^{9} \mathrm{~Hz}\right)$ \\
\hline $\mathrm{Hz}$ & hertz \\
\hline Ka band & frequencies between $26.5 \mathrm{GHz}$ and $40 \mathrm{GHz}$ \\
\hline $\mathrm{K}_{\mathrm{DP}}$ & specific differential phase \\
\hline $\mathrm{kW}$ & kilowatt \\
\hline $\mathrm{m}$ & meter \\
\hline $\mathrm{MHz}$ & megahertz $\left(10^{6} \mathrm{~Hz}\right)$ \\
\hline $\mathrm{mW}$ & milliwatt \\
\hline PPI & Plan Position Indicator \\
\hline PRF & pulse repetition frequency \\
\hline RHI & Range Height Indicator \\
\hline SGP & Southern Great Plains \\
\hline SQI & signal quality index \\
\hline $\mathrm{V}$ & linear channel Doppler mean velocity \\
\hline $\mathrm{W}$ & linear channel Doppler spectrum width \\
\hline W band & frequencies between $75 \mathrm{GHz}$ and $110 \mathrm{GHz}$ \\
\hline X band & frequencies between $8 \mathrm{GHz}$ and $12 \mathrm{GHz}$ \\
\hline X-SAPR & X-band scanning ARM precipitation radar \\
\hline $\mathrm{Z}$ & log channel reflectivity corrected for clutter \\
\hline $\mathrm{Z}_{\mathrm{DR}}$ & differential reflectivity \\
\hline $\mathrm{Z}_{\mathrm{H}}$ & horizontal reflectivity \\
\hline $\mathrm{Z}_{\mathrm{T}}$ & log channel total reflectivity including clutter \\
\hline $\mathrm{Z}_{\mathrm{Y}}$ & vertical reflectivity \\
\hline
\end{tabular}




\section{Contents}

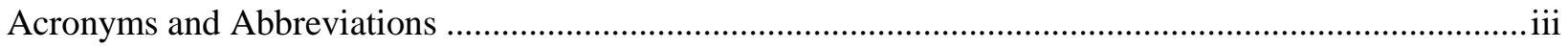

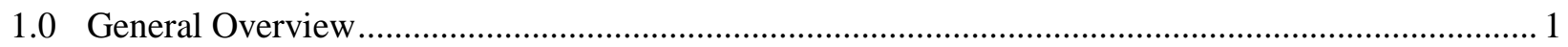

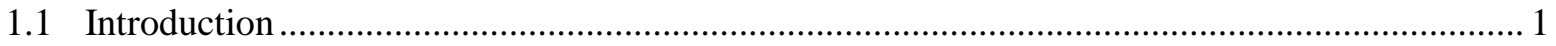

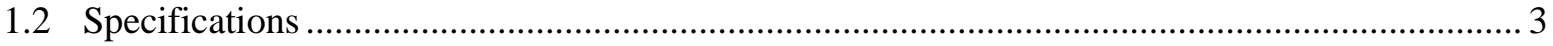

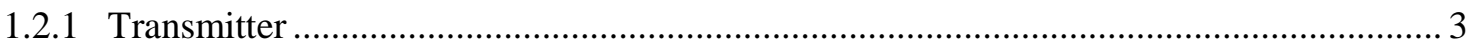

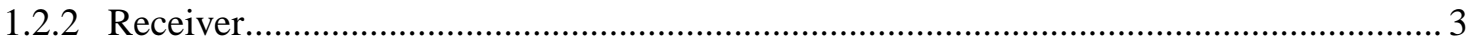

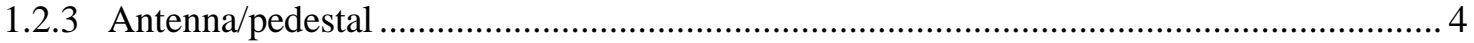

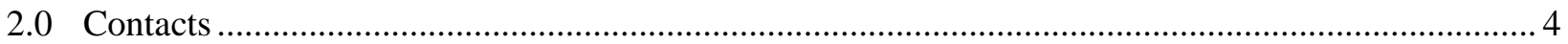

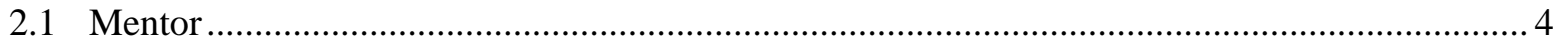

2.2 Vendor/Instrument Developer ............................................................................................ 4

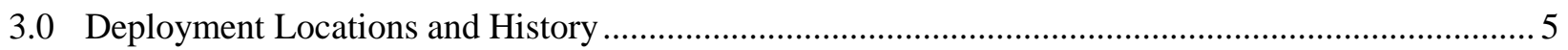

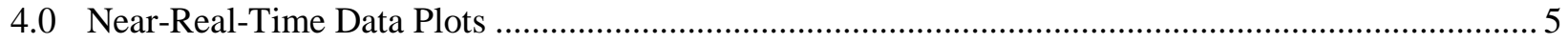

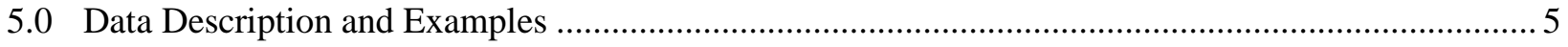

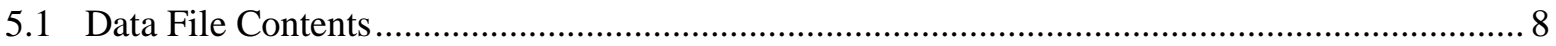

5.1.1 Primary Variables and Expected Uncertainty ............................................................ 8

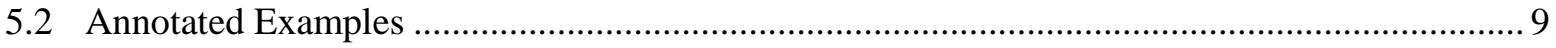

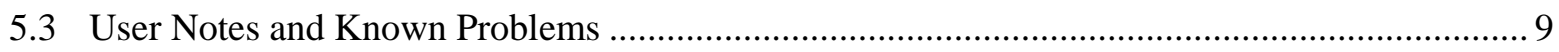

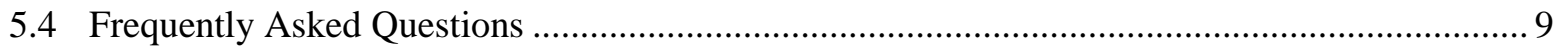

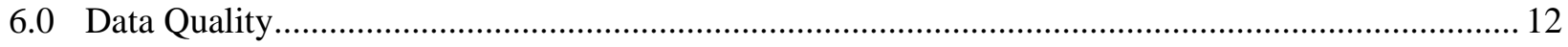

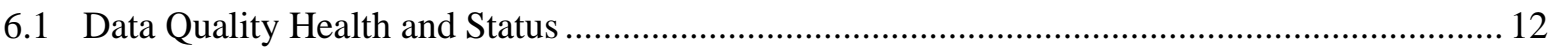

6.2 Data Reviews by Instrument Mentor..................................................................................... 12

6.3 Data Assessments by Site Scientist/Data Quality Office ........................................................ 12

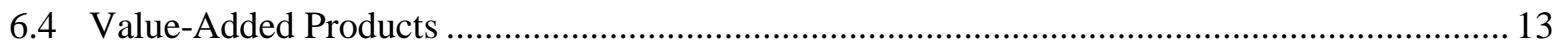

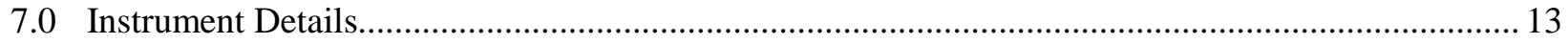

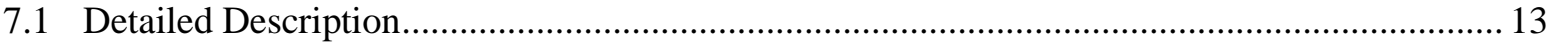

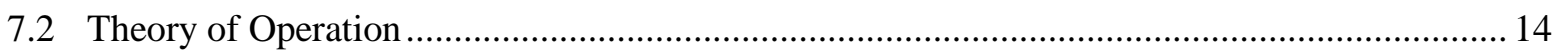

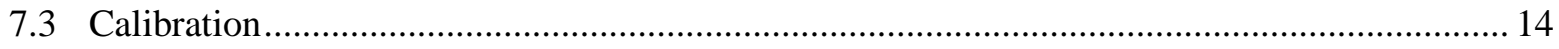

7.4 Operation and Maintenance …….................................................................................. 14

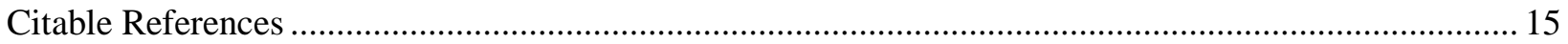




\section{Figures}

Figure 1. X-SAPR installation near Lamont, Oklahoma. ..................................................................... 1

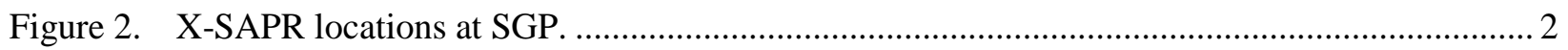

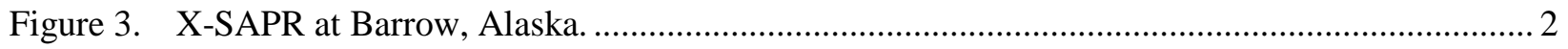

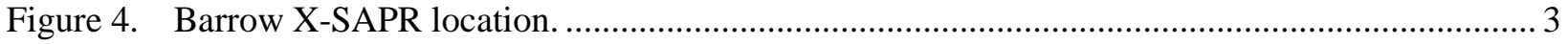

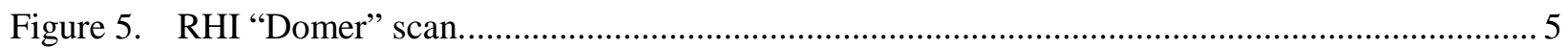

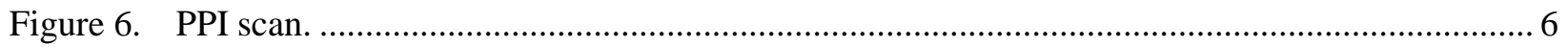

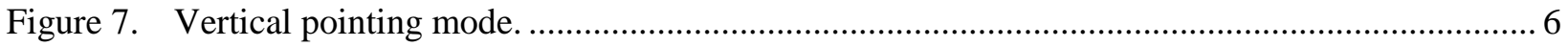

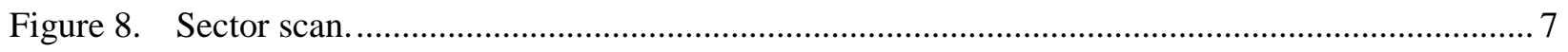

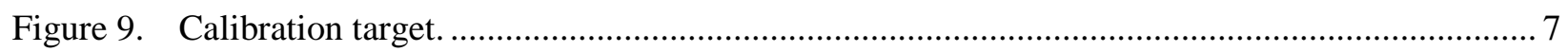

Figure 10. Dielectric function of water as a function of frequency and temperature............................... 10

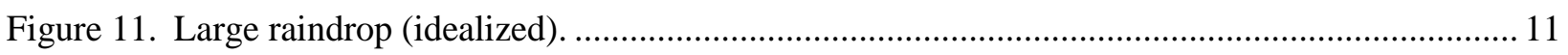

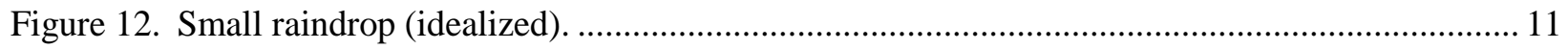

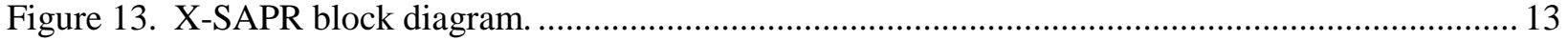

\section{Tables}

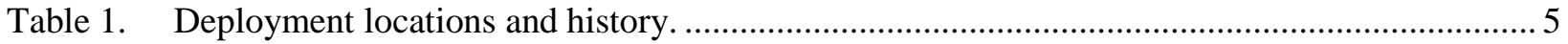




\subsection{General Overview}

\subsection{Introduction}

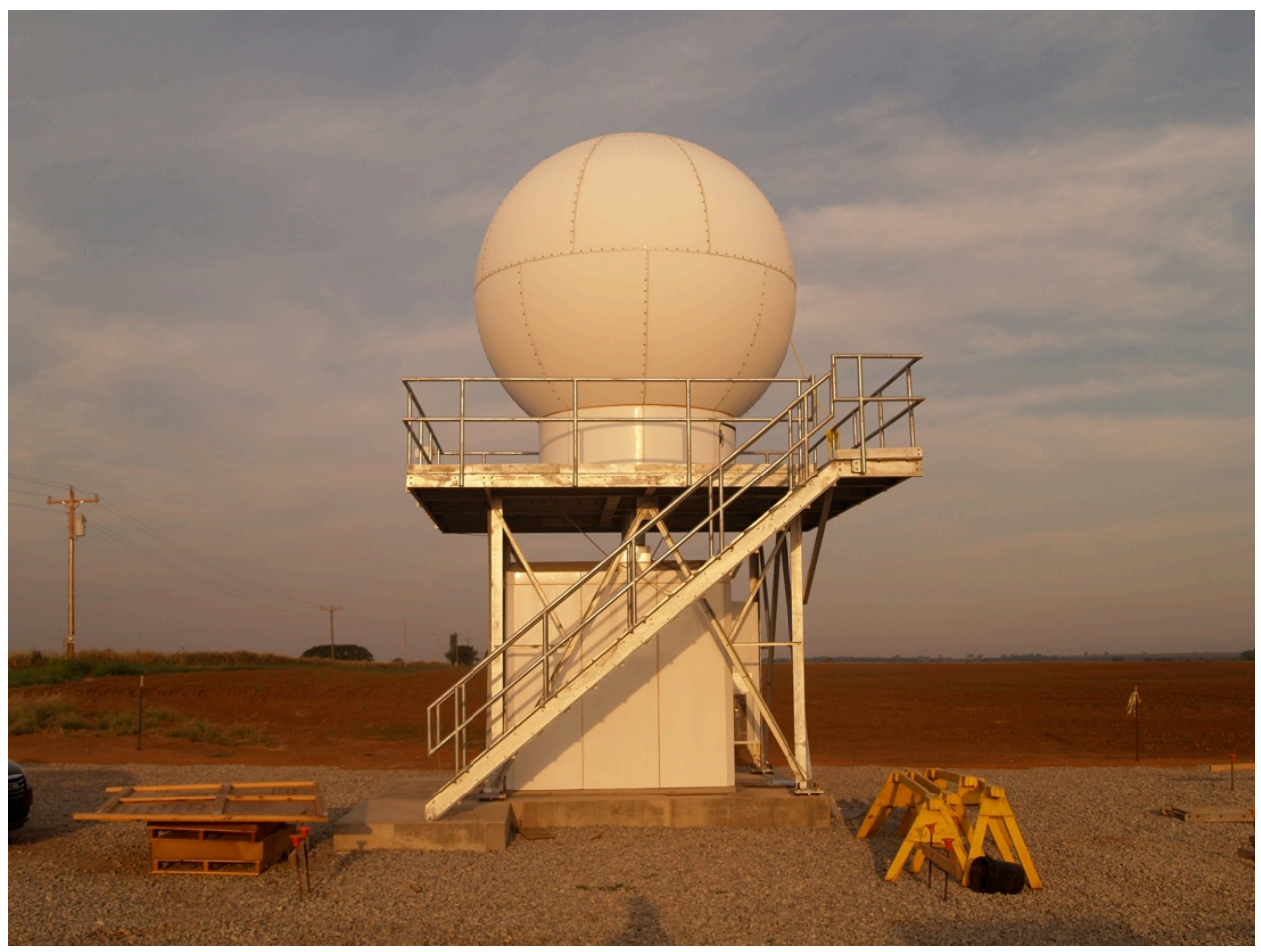

Figure 1. X-SAPR installation near Lamont, Oklahoma.

The X-band scanning ARM cloud radar (X-SAPR) (Figure 1) is a full-hemispherical scanning polarimetric Doppler radar transmitting simultaneously in both $\mathrm{H}$ and V polarizations. With a $200 \mathrm{~kW}$ magnetron transmitter, this puts $100 \mathrm{~kW}$ of transmitted power for each polarization. The receiver for the X-SAPR is a Vaisala Sigmet RVP-900 operating in a coherent-on-receive mode.

Three X-SAPRs are deployed around the Southern Great Plains (SGP) Central Facility (Figure 2) in a triangular array. A fourth X-SAPR is deployed near Barrow, Alaska (Figure 3 and Figure 4) on top of the Barrow Arctic Research Center. 


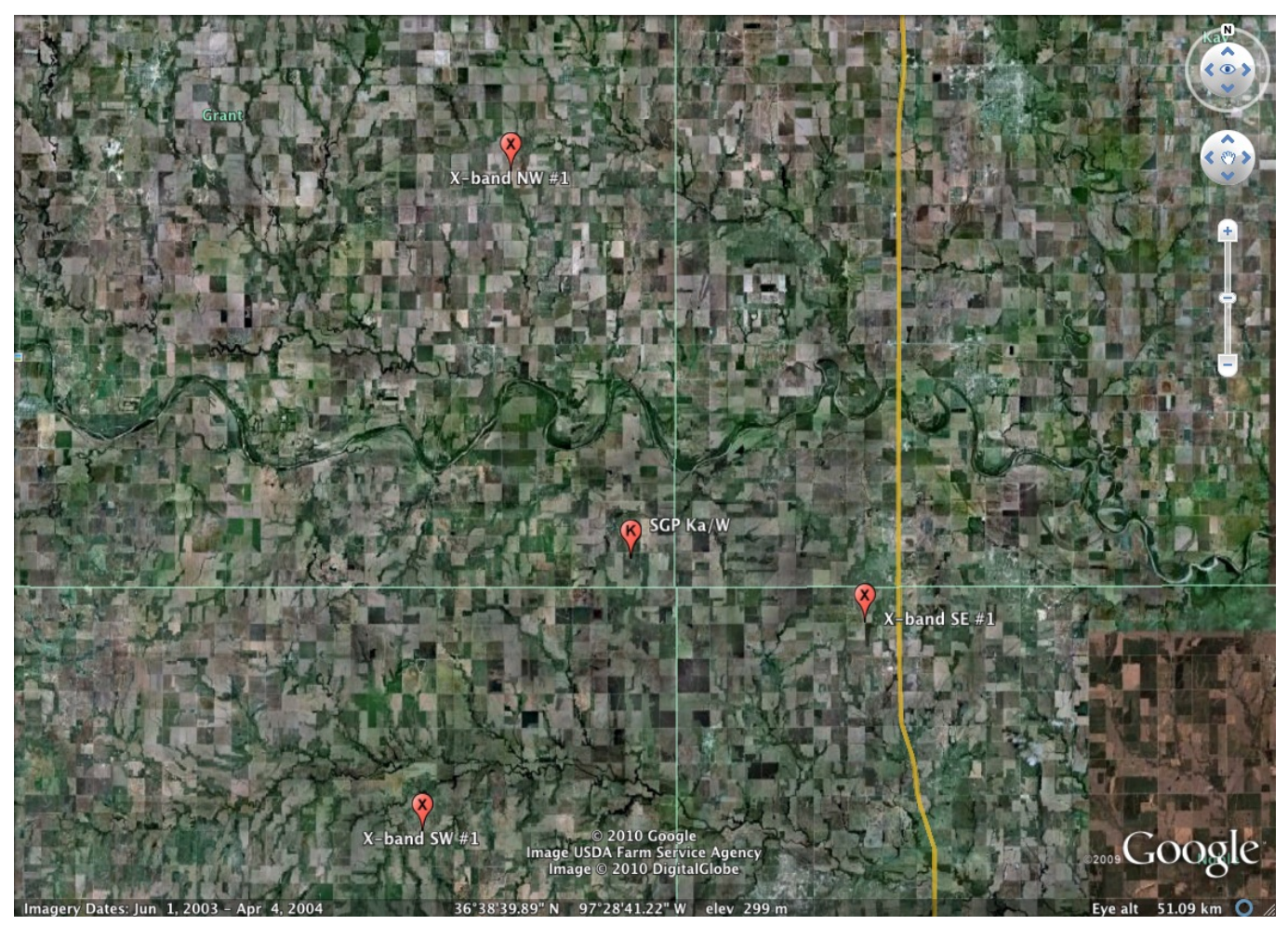

Figure 2. X-SAPR locations at SGP.

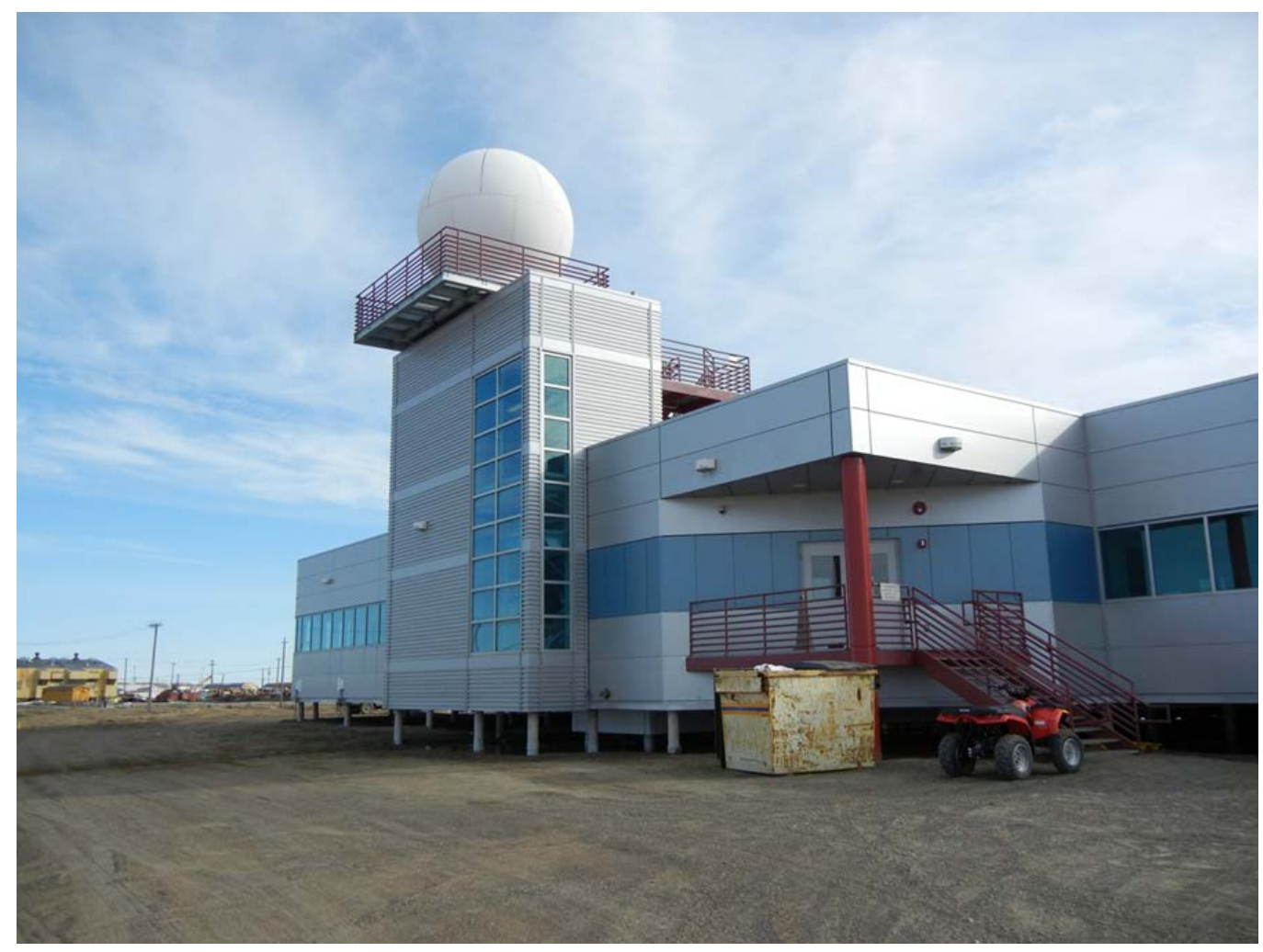

Figure 3. X-SAPR at Barrow, Alaska. 


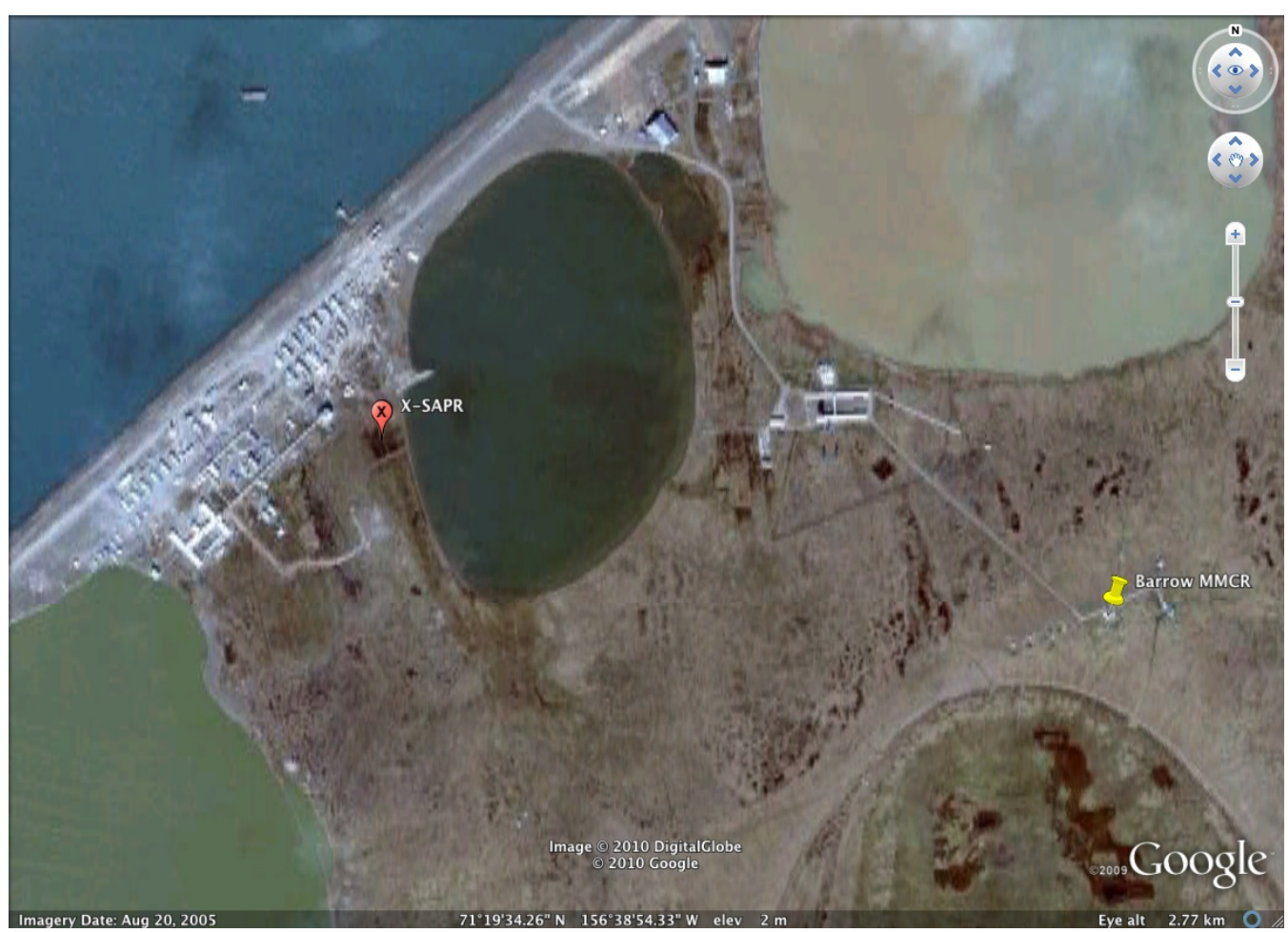

Figure 4. Barrow X-SAPR location.

\subsection{Specifications}

\subsubsection{Transmitter}

Type: Magnetron

Center frequency: $\quad 9.35-9.45 \mathrm{GHz}$

Peak power output: $200 \mathrm{~kW}$

Pulse width: $\quad 200$ ns $-2 \mu \mathrm{s}$

Polarization: dual-polarization, simultaneous $\mathrm{H}$ and $\mathrm{V}$

Maximum duty cycle: $0.1 \%$

PRF: $\quad 200 \mathrm{~Hz}-2.7 \mathrm{kHz}$

Manufacturer: Radtec

\subsubsection{Receiver}

Type:

Dynamic range:

Noise figure:

Sampling rate:

Decimation factor:

Video bandwidth:

Processing software:

Manufacturer: coherent-on-receive, dual channel digital Vaisala RVP-900

$>80 \mathrm{~dB}$

$3.0 \mathrm{~dB}$

$80 \mathrm{MHz}$

Adjustable

Adjustable

IRIS

Vaisala 


\subsubsection{Antenna/pedestal}

Antenna Type: $\quad$ offset feed parabolic reflector

Diameter: $\quad 2.4 \mathrm{~m}$

$3 \mathrm{~dB}$ beam width: $\quad 1.0^{\circ}$

Gain: $\quad 45.0 \mathrm{dBi}$

Cross polarization isolation: $\quad-32 \mathrm{~dB}$

2-way radome loss: $\quad<1.0 \mathrm{~dB}$

Pedestal Type: azimuth over elevation

Azimuth scan rate: up to $36 \%$

Elevation scan rate: up to $30 \%$ s

Pedestal manufacturer: Radtec

\subsection{Contacts}

\subsection{Mentor}

Kevin Widener

Pacific Northwest National Laboratory

412 Hale Drive

Underwood, WA 98651

Phone: 509-375-2487

Fax: 509-375-6736

Email: kevin.widener@pnnl.gov

Nitin Bharadwaj

Pacific Northwest National Laboratory

P.O. Box 999

Richland, WA 99352

Phone: 509-372-4267

Fax: 509-375-6736

Email: nitin@pnnl.gov

\subsection{Vendor/Instrument Developer}

Radtec Engineering, Inc.

2150 W. 6th Ave.

Broomfield, CO 80020

Website: http://www.radar-sales.com 


\subsection{Deployment Locations and History}

Table 1. Deployment locations and history.

\begin{tabular}{|c|c|c|c|c|c|}
\hline Location & $\begin{array}{c}\text { Direction } \\
\text { from } \\
\text { Central } \\
\text { Facility }\end{array}$ & $\begin{array}{c}\text { Site } \\
\text { Designation }\end{array}$ & $\begin{array}{c}\text { Date } \\
\text { Installed }\end{array}$ & $\begin{array}{c}\text { Date } \\
\text { Removed }\end{array}$ & Status \\
\hline $\begin{array}{c}\text { Billings, } \\
\text { Oklahoma }\end{array}$ & SE & SGP/I4 & $12 / 10 / 2010$ & & \\
\hline $\begin{array}{c}\text { Garber, } \\
\text { Oklahoma }\end{array}$ & SW & SGP/I5 & $04 / 20 / 2011$ & & \\
\hline $\begin{array}{c}\text { Lamont, } \\
\text { Oklahoma }\end{array}$ & NW & SGP/16 & $04 / 20 / 2011$ & & \\
\hline $\begin{array}{c}\text { Barrow, } \\
\text { Alaska }\end{array}$ & WNW & NSA/C1 & $06 / 26 / 2011$ & & \\
\hline
\end{tabular}

\subsection{Near-Real-Time Data Plots}

See http://radar.arm.gov.

\subsection{Data Description and Examples}

There are many different types of scans that the X-SAPR can perform. Scan strategies are defined for each site that alternate between the following types of scans:

- RHI (Range Height Indicator) scans are scans in which the azimuth axis is held constant while the elevation axis is changed. An RHI scan can go horizon-to-horizon over 180 degrees of elevation or a subset of that. Figure 5 shows one type of RHI scanning scenario that ARM currently uses, which is also known as a "Hemispherical Sky RHI.” It is a series of horizon-to-horizon RHIs in which the azimuth is incremented. This type of scan provides a good indication of the 3D cloud field.

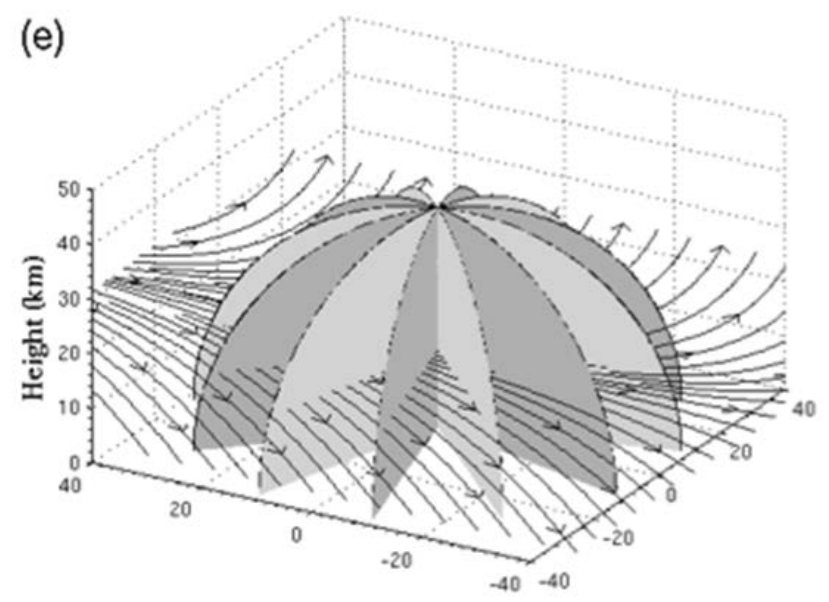

Figure 5. RHI "Domer” scan. 
- PPI (Plan Position Indicator) scans are what are typically thought of when thinking about weather radars. These are scans in which the elevation is scanned for 360 degrees, and then the elevation is incremented. Figure 6 shows a scan with four different elevations.

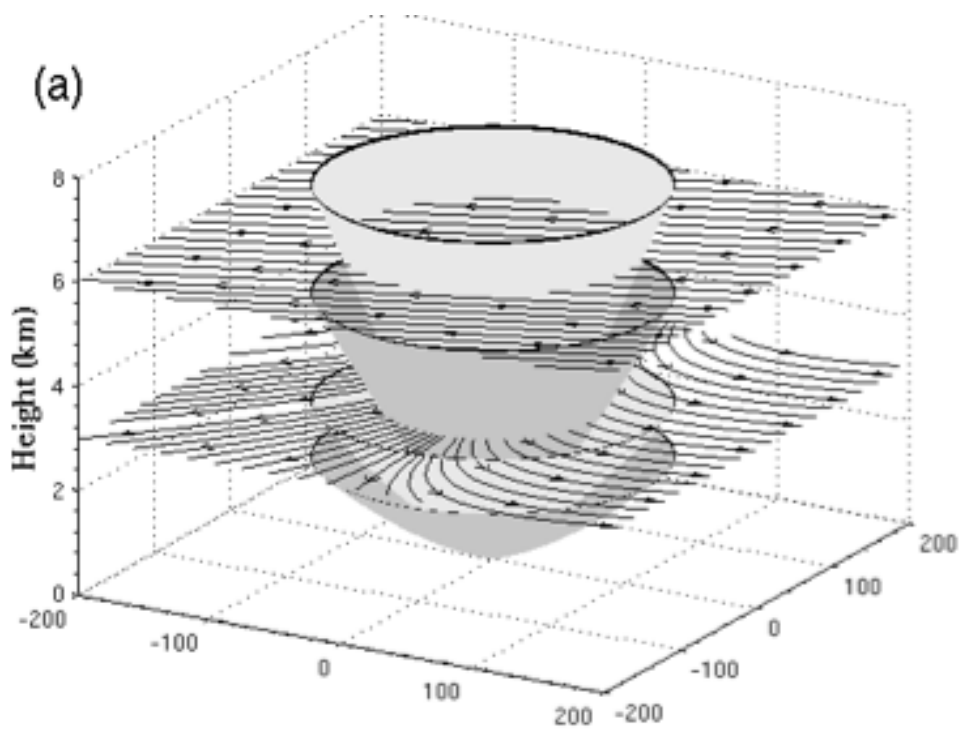

Figure 6. PPI scan.

- Vertical pointing - during part of the measurement period, ARM plans on operating the X-SAPR in a vertical-pointing mode to obtain zenith cloud profiles similar to those obtained by the Ka-band ARM zenith radar and W-band ARM cloud radar. Figure 7 shows an example of this type of scan.

(c)
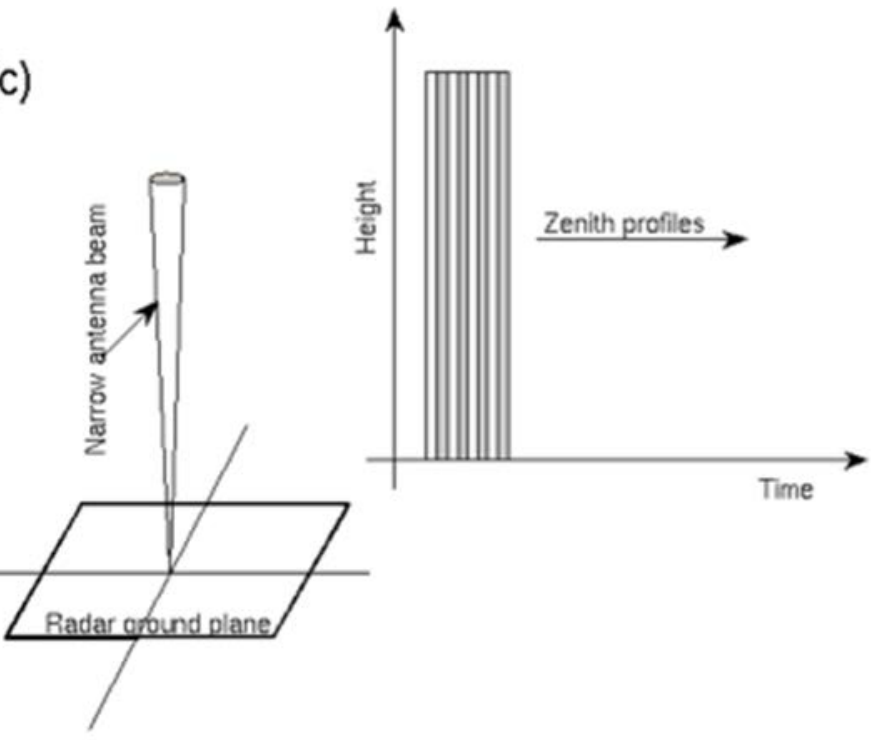

Figure 7. Vertical pointing mode. 
- Sector Scan - elevation scans along a particular azimuth have proven to be desirable among researchers. Typically, these are sector scans are perpendicular to the prevailing wind direction as shown in Figure 8. However, there are times when it is desired to perform sector scans in parallel with the wind direction. These sector scans must be set up manually by the radar instrument mentor.

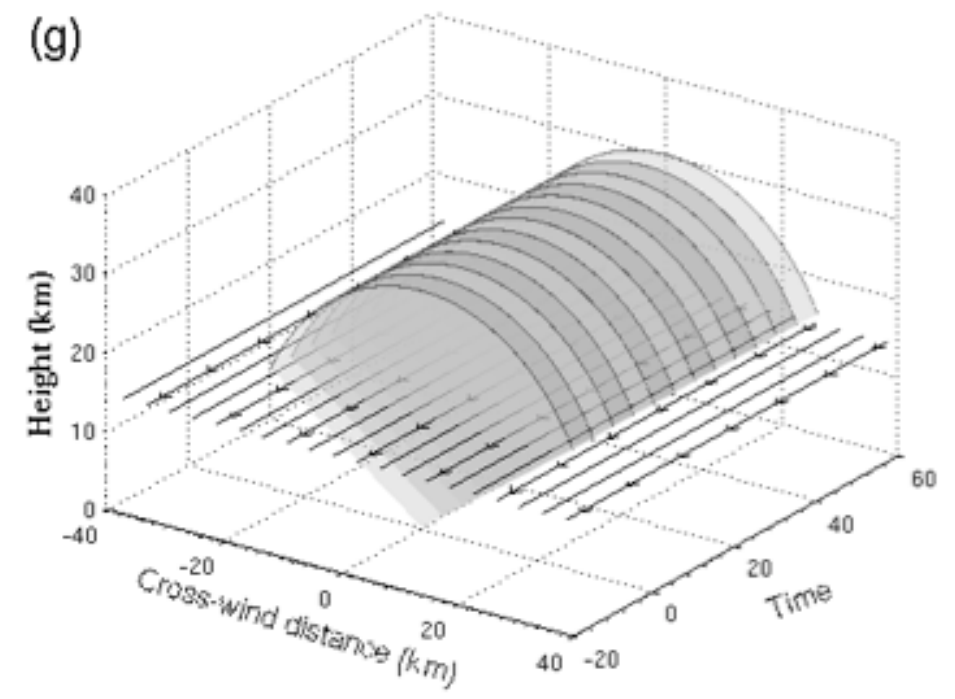

Figure 8. Sector scan.

- Calibration - one of the great benefits of having a scanning radar with a relatively narrow beamwidth is the ability to look at a fixed target of known radar cross-section to provide an absolute calibration point for the X-SAPR. In this mode, the X-SAPR points at a predetermined fixed azimuth and elevation for the corner reflector. Figure 9 shows an example of calibration.

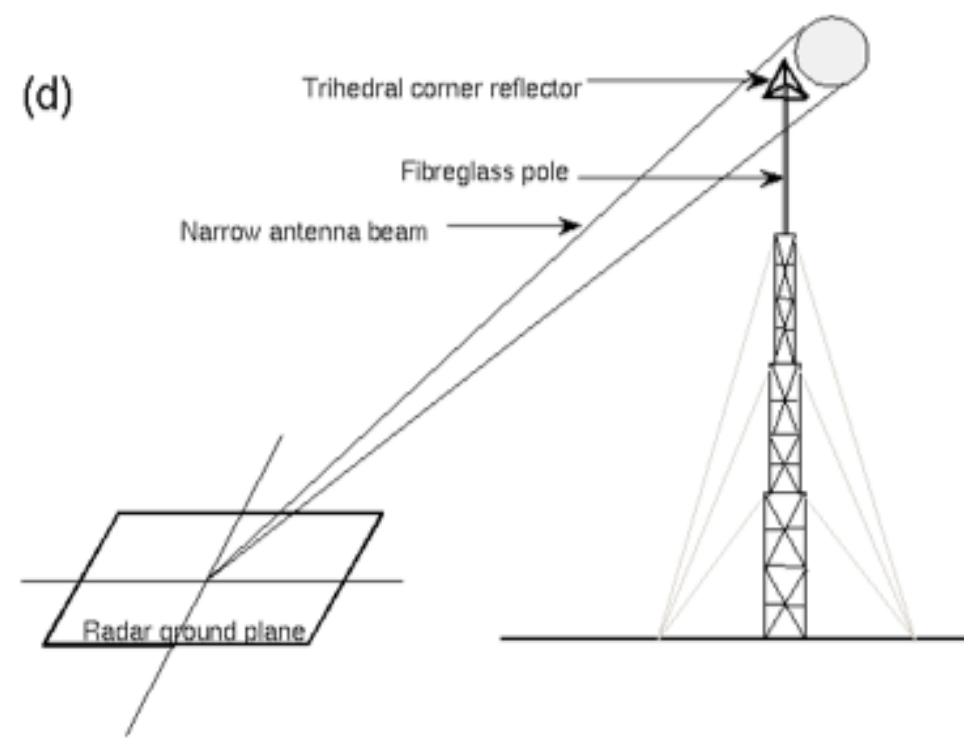

Figure 9. Calibration target. 


\subsection{Data File Contents}

For the time being, ARM has decided to not ingest the X-SAPR data into netCDF. X-SAPR data are stored in the IRIS format developed by Vaisala (formerly Sigmet). Data file descriptions are given in Vaisala's IRIS documentation. A free version of IRIS software for viewing data is available from Vaisala at: http://www.vaisala.com/en/defense/products/weatherradar/Pages/IRIS.aspx

Click on the "Fee Display License" and fill out the form.

Below is an example of the PPI header information that is available from the IRIS file:

Site name: 'xsapr-sgpr3', Task name: 'MC3E_CNV_PPI'

Scan: PPI, Speed: $26.00 \mathrm{deg} / \mathrm{sec}$, Resolution:0.90 deg

Description: 'MC3E Convective Volume scan '

Location: 36 34.7'N 97 21.8'W, Altitude: 346 meters, Melting height:Unknown

Volume Time: 20:06:43.967 29 MAY 2012 UTC (0 min. west) (LT: CDT 360 min.)

ZFlags: sp_t, block_zc, attn_zc, target_zc, DPATTEN_ZC, dpatten_z

VFlags: sp_v, 3lag_w, ship_v, unfold_vc, fall_vc, storm_vc

PRF: 2222Hz, PulseWidth: 0.37 usec (0)

BeamWidth: 1.18/1.02 deg.

Radar constant: 72.45/72.45 dB, Receiver bandwidth $2476 \mathrm{kHz}$.

Calibration I0: -106.13/-105.62 dBm, with noise -72.40/-72.56 dBm.

LOG-Noise: 0.3769, Lin-Noise: 0.3769, I-Off: 0.0000, Q-Off: 0.0000

SOPRM Flags: 0x3681, LOG Slope: 0.640, Z-Cal: -33.69dBZ, H/V: -2.00 dB

Filters: Dop:0, Log:0; PntClt: 0, Thresh: $0.0 \mathrm{~dB}$; Samples: 90

Processing Mode: PPP, Xmt Phase: Random

T Threshold: All Pass

$\mathrm{LOG}=0.8 \mathrm{~dB}$

Z Threshold: All Pass

$\mathrm{SIG}=5.0 \mathrm{~dB}$

V Threshold: All Pass

$\mathrm{CSR}=18.0 \mathrm{~dB}$

W Threshold: All Pass

$\mathrm{SQI}=0.40$

Zdr Threshold: All Pass

$\mathrm{PMI}=0.00$

Differential offset GDR $=0.00 \mathrm{~dB}$ De-polarization offset XDR $=0.00 \mathrm{~dB}$

Available moments are: dBT2 dBZ2 V2 W2 ZDR2 Kdp2 RhoHV2 dBZc2 SQI2 PhiDP2 ZDRc2

Original moments were: dBT2 dBZ2 V2 W2 ZDR2 Kdp2 RhoHV2 SQI2 PhiDP2

Starting range $0.000 \mathrm{~km}$, range bin spacing 50 meters

There are 22 sweeps, each having 400 rays and 801 bins

$\begin{array}{llllllllllllll}\text { Angle list: } & 0.5 & 1.5 & 2.5 & 3.5 & 4.5 & 5.5 & 6.5 & 7.5 & 8.5 & 9.5 & 10.5 & 11.5 & 12.5\end{array}$

$\begin{array}{lllllllll}14.0 & 17.0 & 20.0 & 25.0 & 30.0 & 35.0 & 40.0 & 45.0 & 50.0\end{array}$

\subsubsection{Primary Variables and Expected Uncertainty}

V Linear channel Doppler mean velocity

W Linear channel Doppler spectrum width

Z Log channel reflectivity corrected for clutter

$\mathbf{Z}_{\mathbf{T}} \quad$ Log channel total reflectivity including clutter

$\mathbf{Z}_{\text {DR }} \quad$ Differential reflectivity

$\phi_{\mathrm{DP}} \quad$ Differential phase 
$\mathrm{K}_{\mathrm{DP}} \quad$ Specific Differential phase

$\rho_{\mathrm{HV}} \quad$ Dual polarization correlation magnitude

SQI Signal quality index

\subsection{Annotated Examples}

To be determined.

\subsection{User Notes and Known Problems}

To be determined.

\subsection{Frequently Asked Questions}

What is the meteorological radar range equation?

This is the equation to determine the reflectivity and is usually given in decibels of $\mathrm{Z}$ or $\mathrm{dBZ}$.

$$
Z=10 \log \left(\frac{1024 \ln (2) \lambda^{2} R^{2} P_{r} L_{a} L_{s y s}}{\left.10^{-18} c \tau \pi^{3} G_{0}^{2} K_{w}\right|^{2} \theta_{3 d B}^{2} P_{t}}\right) \quad d B Z
$$

where:

$\mathrm{Z}=$ reflectivity $(\mathrm{dBZ})$

$\lambda=$ wavelength $(\mathrm{m})$

$\mathrm{R}=$ range $(\mathrm{m})$

$\mathrm{P}_{\mathrm{r}}=$ received power (watts)

$\mathrm{L}_{\mathrm{a}}=$ two-way atmospheric loss

$\mathrm{L}_{\text {sys }}=$ radar system losses

$\mathrm{c}=$ speed of light $(\mathrm{m} / \mathrm{s})$

$\tau=$ pulse width (s)

$\mathrm{G}_{0}=$ antenna gain

$\left|\mathrm{K}_{\mathrm{w}}\right|^{2}=$ index of refraction factor for liquid water at $0 \mathrm{C}$

$\theta_{3 \mathrm{~dB}}=$ antenna beamwidth

$\mathrm{P}_{\mathrm{t}}=$ transmit power (watts)

What dielectric factor for water is used to computer reflectivity in the radar range equation $/ K_{w} / 2$ ?

The dielectric factor of water is a function of frequency and temperature of water drops as shown in Figure 10. 


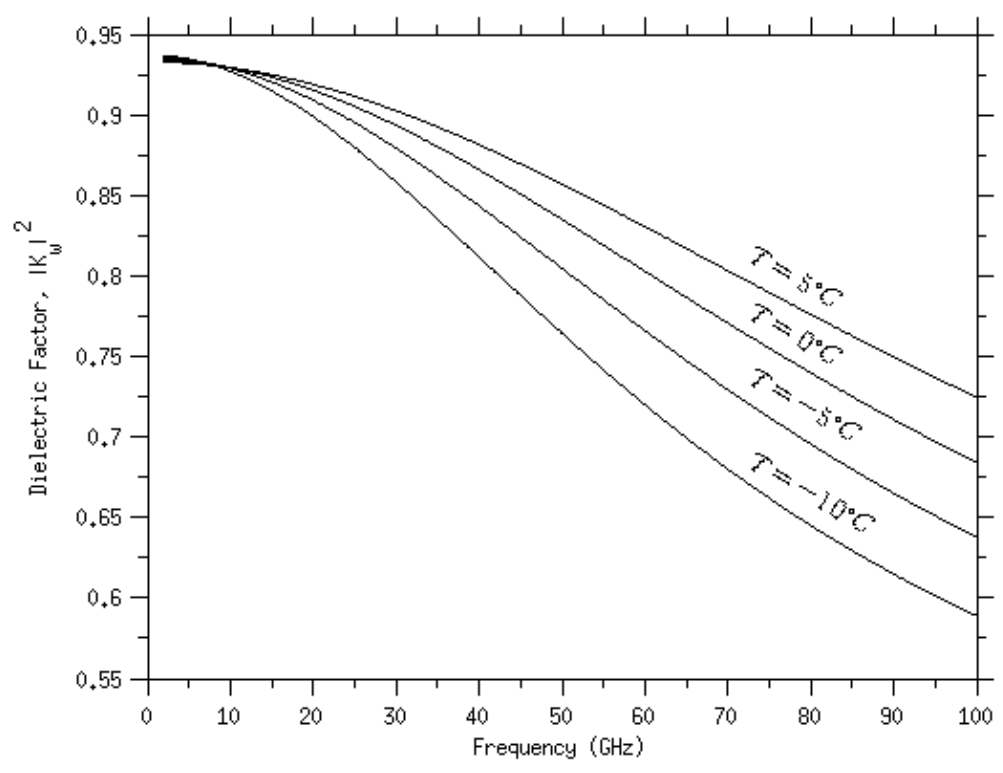

Figure 10. Dielectric function of water as a function of frequency and temperature.

The dielectric factor of water at $0^{\circ} \mathrm{C}$ is used for the computation of equivalent reflectivity factor. The value of dielectric factor used is 0.93 for X-SAPR.

\section{What are measurements are made with a dual-polarization radar versus that of a single polarization radar?}

All Doppler weather radars provide a measurement of equivalent radar reflectivity factor (colloquially just reflectivity). Single-polarization radars cannot distinguish much in the way of the type of hydrometeor being observed. They also have varying degrees of success in estimating rainfall rates, and they depend on empirically derived parametric models to do this. These models are different for differing climatic regimes. The promise of dual-polarization techniques is to alleviate some of these shortcomings.

To understand the role of dual-polarization radars in meteorology, it is useful to consider the shape of water droplets. They are not always spherical, nor are they shaped like the customary teardrop. Water droplets are roughly oblate spheroids for larger drops and spherical for small drops. The larger the drop, the larger the horizontal axis is with respect to the vertical axis (Figure 11). Smaller drops are much closer to being spherical (Figure 12). 


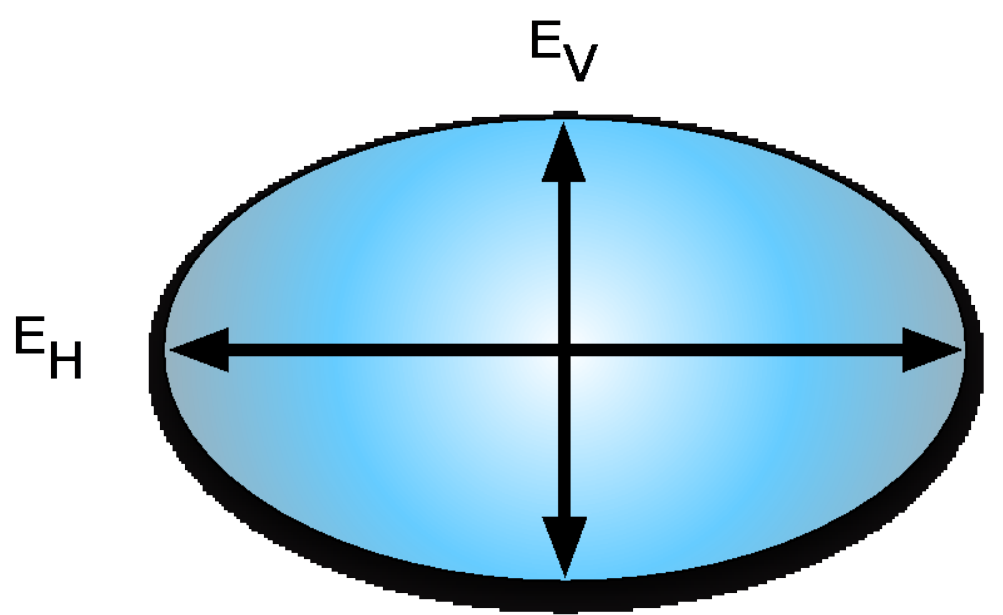

Figure 11. Large raindrop (idealized).

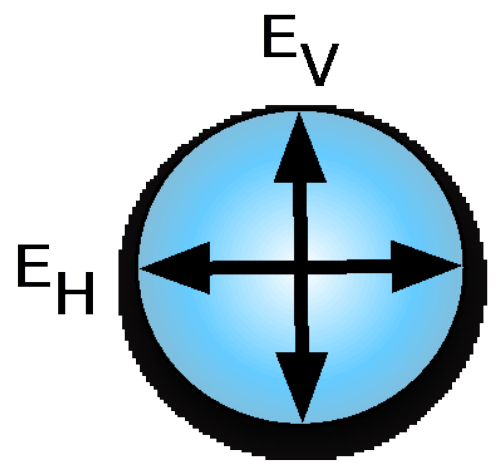

Figure 12. Small raindrop (idealized).

Keeping in mind the oblateness of raindrops, dual polarization adds the ability to measure the following variables:

- Horizontal reflectivity $\left(\mathrm{Z}_{\underline{H}}\right)$ is a measurement of the reflectivity in the horizontal polarization plane. For large raindrops, the reflectivity in the horizontal axis is going to be much larger than that in the vertical axis, i.e., more oblate the larger the drop is.

- Vertical reflectivity $\left(Z_{\mathbb{V}}\right)$ is a measurement of the reflectivity in the vertical polarization plane. As the raindrop gets smaller, it becomes more like a sphere, i.e., less oblate smaller the drop is.

- Differential reflectivity $\left(\mathrm{Z}_{\mathrm{DR}}\right)$ is the ratio of the horizontal reflectivity $\left(\mathrm{Z}_{\mathrm{H}}\right)$ to the vertical reflectivity $\left(\mathrm{Z}_{\mathrm{v}}\right)$. For large water drops, $\mathrm{Z}_{\mathrm{H}}>\mathrm{Z}_{\mathrm{v}}$ and $\mathrm{Z}_{\mathrm{DR}}>0 \mathrm{~dB}$. For small drops, $\mathrm{Z}_{\mathrm{H}} \approx \mathrm{Z}_{\mathrm{v}}$ and $\mathrm{Z}_{\mathrm{DR}} \approx 0 \mathrm{~dB}$. What about ice in the form of hail? Although hail is irregularly shaped, as it tumbles during its rise and fall in the atmosphere, it looks close to spherical and its $\mathrm{Z}_{\mathrm{DR}} \approx 0 \mathrm{~dB} . \mathrm{Z}_{\mathrm{DR}}$ is unitless and reported in $\mathrm{dB}$.

- Differential propagation phase shift ( $\phi_{D \mathrm{DP}}$ ) is the measured two-way cumulative differential phase shift between the horizontal signal $\left(\phi_{\mathrm{HH}}\right)$ and the vertical signal $\left(\phi_{\mathrm{VV}}\right)$. As the radar signal goes through water, its speed is reduced for that period of time it is in a raindrop, inducing a phase delay in the signal. In large oblate drops, this phase delay, also called phase shift, is larger than smaller less oblate drops. $\phi_{\mathrm{DP}}$ is measured in degrees. 


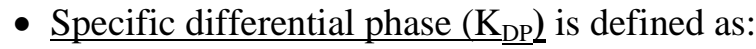

$$
K_{D P}=\frac{\phi_{D P}\left(r_{2}\right)-\phi_{D P}\left(r_{1}\right)}{2\left(r_{2}-r_{1}\right)}\left(\frac{\operatorname{deg}}{\mathrm{km}}\right)
$$

$\mathrm{K}_{\mathrm{DP}}$ is useful for estimating rainfall rates because it is not affected by spherical particles (i.e., tumbling hail). This allows the amount of liquid water in a rain-ice mixture to be estimated. Another important feature of $\mathrm{K}_{\mathrm{DP}}$ is that it is a propagation variable, which means it is not dependent on the amount of received power.

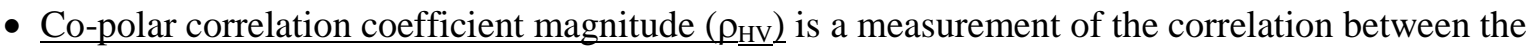
horizontal and vertical radar signals. $\rho_{\mathrm{HV}}$ can be useful in hydrometeor discrimination, e.g., differentiating between rain, hail, graupel, snow, etc.

\subsection{Data Quality}

\subsection{Data Quality Health and Status}

The Data Quality Office website has links to several tools for inspecting and assessing X-SAPR data quality:

- $\underline{\text { DQ Explorer }}$

- $\underline{\text { DQ Plot Browser }}$

- NCVweb: Interactive web-based tool for viewing ARM data.

Plots of reflectivity, Doppler radial velocity, and dual-polarization variables provide a good indicator of whether the system is operational or not.

\subsection{Data Reviews by Instrument Mentor}

Instrument mentors review X-SAPR data in the following ways:

- Routine review for nominal operation, usually daily Monday-Friday

- When requested by Site Operations

- When requested by the site scientist team

- When requested by an ARM data translator

- When requested by a data user

- When notified automatically by the X-SAPR's built-in test (BIT) email messages.

\subsection{Data Assessments by Site Scientist/Data Quality Office}

To be determined. 


\subsection{Value-Added Products}

There are no value-added products for the X-SAPR at this time. There are plans to produce a "corrected moments” product, which will include velocity and range dealiasing and water vapor attenuation correction. After that, a gridded moments product with cloud boundaries will be produced.

\subsection{Instrument Details}

Instrument details are available in the manufacturer's documentation. Contact the instrument mentor for information.

\subsection{Detailed Description}

The following figure shows the basic block diagram for the X-SAPR. There are four major functional groups: (1) Transmitter Group, (2) Receiver Group, (3) Antenna Group, and (4) Data Processing and Control Group.

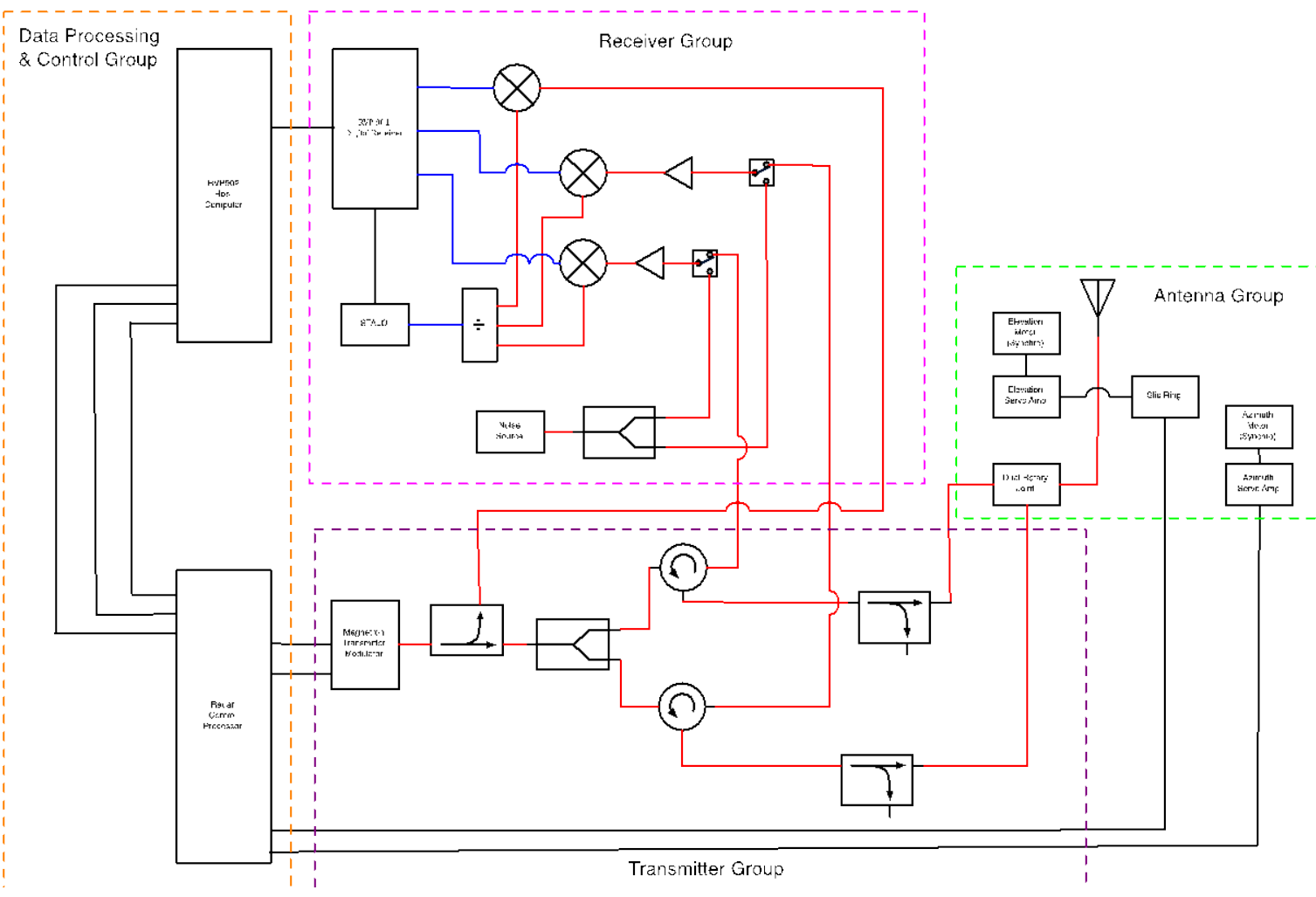

Figure 13. X-SAPR block diagram.

\section{Transmitter Group}

- Type:

- Power:

- Frequency:

- Duty Cycle:

- Pulse Widths:
Magnetron

$>100 \mathrm{~kW}$ peak

$\sim 9.45 \mathrm{GHz}$

$0.1 \%$

0.2-2.5 microseconds 


\section{Receiver Group}

- Front End: $\quad<3 \mathrm{~dB}$ noise figure for Low Noise Amplifier/Mixer

- IF: $60 \mathrm{MHz}$

- Processor: Vaisala RVP901

- Digitizer: 16-bit

- Dynamic range: $\quad>100 \mathrm{~dB}$ with digital signal processing

\section{Antenna Group}

- Type: 2.4 meter offset feed

- Beamwidth: $\quad \sim 1.0$ degree

- Gain: $44 \mathrm{~dB}$

- Control: Digital 2-axis servo with position/velocity feedback

- Motors: 400-750 W servo

- Drive: Digital torque amplifier

- Position Sense: Synchro

\section{Data Processing \& Control Group}

- Operating system: Linux

- System software: Vaisala IRIS

- Control: Radtec Radar Control Processor

\subsection{Theory of Operation}

The theory of operation is available in the manufacturer's documentation. Contact the instrument mentor for information.

\subsection{Calibration}

To be included in manufacturer's documentation and the ARM Common Calibration (CCDB) database. Contact the instrument mentor for information.

\subsection{Operation and Maintenance}

Operation and maintenance information is available in the manufacturer's documentation. Contact the instrument mentor for information. 


\section{Citable References}

Bharadwaj N, K Widener, A Koontz, and K Johnson. "Data Specification for ARM Scanning Radars.” In progress.

Bringi VN and V Chandrasekar. 2001. Polarimetric Doppler Weather Radar. Cambridge University Press, Cambridge, United Kingdom.

Doviak RJ and DS Zrnic. 1993. Doppler Radar and Weather Observations. $2^{\text {nd }}$ Edition, Academic Press, San Diego, California. 


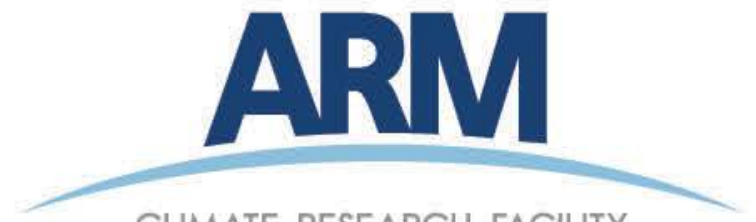

CLIMATE RESEARCH FACILITY

www.arm.gov

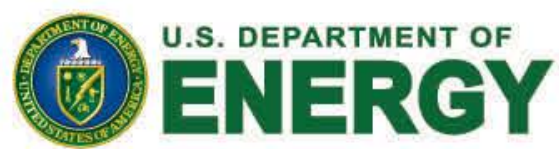

Office of Science 